\title{
Disability Play Therapy: Implementation of Traditional Japanese Game to Improve Creativity and Education in Public Special Needs Inclusive School (SLB) 1 Makassar
}

\author{
Ria Rosdiana Jubhari ${ }^{1 *}$,Teguh Daniel Bandaso ${ }^{1}$, Nurul Hidayah ${ }^{1}$, Zilzi Zabila ${ }^{1}$, \\ Mochammad Afiq Gizly ${ }^{1}$, Andi Juwita $\mathrm{Amal}^{2}$
}

${ }^{I}$ Department of Chinese Literature, Faculty of Literature, Universitas Hasanuddin, Makassar

${ }^{2}$ Department of Psychology, Faculty of Medicine, Universitas Hasanuddin, Makassar

*Corresponding author. Email: riajubhari@unhas.ac.id

\begin{abstract}
People with disabilities generally experience physical, mental, and sensory limitations - this limitation results in barriers and difficulties in interacting with their environment. Education offered at the special needs school (SLB) only provides reading and writing skills. Despite these, it is necessary to hone their inner skills to be optimal with their conditions. Kegiatan Program Kreativitas Mahasiswa Bidang Pengabdian Masyarakat (Student Creativity Event) designed the Disability Play Therapy which aims to hone creativity. This activity adapts the concept of Japanese traditional children's games that are creative and safe for children with disabilities. The activity is held for three months, including the preparations, program implementation, evaluation, and mentoring for the teachers. The program was attended by twelve students from SLB (Special Needs School) 1 Makassar and consisted of four disabilities, namely intellectual disability, physical disability, hearing disability, and autism. The program's aftermath resulted in children with disabilities managing to play traditional Japanese children's games, including improving their cognitive abilities, fine motor skills, and creativity. Based on the results and aftermath of the program. This program is highly recommended to implement disability play therapy as a model for learning activities.
\end{abstract}

Keywords: play therapy, disability, Japanese games.

\section{INTRODUCTION}

Special needs school, commonly known in Indonesia as "Sekolah Luar Biasa" (SLB), is a formal school for children with disabilities to gain basic services to help them get better access to education. Disabilities are defined as a condition of individuals who experience intellectual, physical, mental, and sensory limitations for an extended period of time. This limitation results in obstacles and difficulties in interacting with their environment. The learning process in special needs schools (SLB) is ideally adapted to cater to the needs of every disability. Likewise, this is shown to be the case for the school which this activity took place.
The pandemic condition also affected the learning process at SLB Negeri 1 Makassar. The learning process, which was usually carried out directly from schools, was eventually shifted to online learning, with teachers assigning some homework to the children. The children's parents now have to act as the teacher's assistant at home. However, this did not go so well due to parents' difficulty teaching and children being more challenging to direct. With this condition, there is almost no learning process that can take place, due to this also results in a lack of improvement in children abilities. Parents could only hope that the school can implement the offline teaching method again with this condition.

Entering the second year of the COVID-19 pandemic, several schools, including a few special needs schools, are conducting limited face-to-face 
learning. However, due to the previous offline learning process, children do not experience an improvement in their abilities. The learning process for the disabilities they have and experienced. This therapeutic effect of learning can provide children with disabilities some form of support in learning and doing their daily activities. For example, fine motor skills are needed to master certain abilities to use stationery, eat, and other ability. In addition, the tedious learning process that is generally implemented in special needs schools can make children bored and not enthusiastic about participating in learning activities.

This problem currently plagued the special schools; due to this, we try to find the right solution by involving cultural studies. We try to formulate the concept of fun learning by involving a therapeutic process that can improve the abilities of children with disabilities. The solution we provided through this research is Disability Play Therapy. This solution is a learning activity using the playing method combined with the therapy process. Based on the results of previous research, an effective learning process ideally involves fun activities, such as playing. In addition, playing with physical objects is more manageable for children with disabilities to learn. Previous research by Muthia proves that playing activity has many functions, including stimulating children's development, developing children's abilities and potentials, and recognizing objects and situations related to the learning process in traditional schools [1].

We tried to research many suitable games and decided to use traditional games. According to Nur, traditional games have many similar characteristics with the environment and have a solid physical form compared to digital games [2]. We decided to choose traditional Japanese games from various traditional games in East Asia as part of the Disability Play Therapy activities. This decision in traditional Japanese games is due to the simplicity and easier instruction than traditional Indonesian games. Indonesian traditional games are generally very difficult for children with disabilities. In addition, the traditional Japanese games that we choose as a part of the activity are human figurines with attractive colors and game instructions that are easy for children with disabilities to play. In addition, we are trying to introduce Japanese culture to broaden the horizon of knowledge from children with disabilities.

The main objectives of this program are to improve the physical, cognitive, emotional, and social skills of children with disabilities through traditional Japanese games and culture that is adaptive to the Indonesian culture. Other objectives at these inclusive schools generally emphasizes the read, writing, and counting activities and does not involve a therapeutic effect as a form of intervention include the fostering of creativity in children with disabilities.

Benefits that could be gained from this program are the children's abilities to develop and become more optimal in accordance with the condition of their disabilities. In addition, the teachers can also learn a new method as a variation in the classroom learning process, which can cause the children to become more enthusiastic about their activities.

The potential that can be achieved from this program includes the availability of learning methods that combine play activities and therapy so that children with disabilities can develop optimally despite their condition. They can be more responsive to the social interactions to develop themselves into children with a process of self-change in personality, self-confidence, responsiveness, emotional, psychological, and actively communication with other people around them. This process can help them to develop their potential to the fullest. Another potential is that teachers in special needs schools can find another variation of methods used in classroom learning.

\section{METHOD}

We partnered with an special needs school called Sekolah Luar Biasa Negeri Pembina Tingkat Provinsi or commonly refered as SLB Negeri 1 Makassar. The special needs school is located in Daeng Tata Street, Makassar City. These schools provide learning for students with many disabilities such as visually impaired, physically impaired, hearing impaired, and mental retardation.

The subjects participating in this program were three physically impaired children, three hearingimpaired children, four mentally retarded children, and two children with autism. All the participants are aged between 7 to 13 years old. The consideration for this participant's criteria is due to the possibility of them participating in games. Another consideration for this age group was that it is still an age referred to as the playing age.

The implementation of this program starts from July to August of 2021. The program includes a series of activities that are the program's core activities. The program was also carried out with offline methods with strict health protocol methods.

The first step in this program was to approach and analyze the potential and abilities of children with periodic evaluation. Interventions are carried out 
repeatedly with the same methods and games to observe the children's development and abilities. Implementing the play guidance system is carried out once a week, with each meeting lasting to 90 minutes with the targets of four to six meetings. In implementing play guidance activity, each disability group is accompanied by one team and one volunteer. The activity is supervised by one teacher who acts as a chaperone.

The traditional Japanese games used in this program are kendama, fukuwarai, daruma otoshi, puzzle, kokeshi, koi fish, hinamatsuri, and origami. All of which are given to the participants.

\subsection{Kendama (けん玉)}

Kendama is a toy with a cross shape. The meaning of the name is "ken (sword)" and ball with a hole called "Tama."

This toy use three slopes that fit the holes inside the ball. The game is similar to the classic cup and ball game. The goal is to catch one object and use the ken to catch the ball in the bowl-shaped slope part of the toy or on top of the ken (sword).

\subsection{Fukuwarai（福笑 (1)}

Fukuwarai (福笑() is a traditional game played during Japanese New Year's Eve. This game is played with the figurine of a cute woman (usually called okame or otafuku). However, parts of the face such as the eyebrows, eyes, nose, and lips are attached on separate paper. This game share similarity with connects the donkey tail game [3].

The instruction of this game is to close the eyes, and then the participants try to attach the parts of the face to the right place. If the parts of the face were attached in the wrong place, it could create an odd picture that could break some laughs from the participants. The winner of this game is the one with the funniest looking results or the one who can attach all the right parts.

\subsection{Daruma Otoshi (だるま落とし)}

Daruma Otoshi or "Failing Buddha" is a traditional Japanese game based on a doll called daruma, which looks like Bodhidharma, the founder of Zen Buddhism. The daruma doll imitates Bodhidharma, who found Zen Buddhism. Usually, this toy consists of 5 separate stacks of tall cylindrical wood. Each of the stacks has different colors. The game consists of knocking down each piece with a small wooden hammer, starting at the bottom, without disturbing the rest of the pile until only the head is left.

The game is played by hitting the wooden disc of the lowest pile using a hammer as hard as possible until it detaches from the arrangement, provided that the top arrangement must not be dismantled or remain in its arrangement.

\subsection{Puzzle}

The puzzle is a game consisting of rearrangement of parts to complete the picture. Children are taught to remember shapes and arrange them back correctly in this game.

The benefits of playing puzzles help children understand and follow directions to achieve a goal. This game can also train the memory when children try to remember parts of pictures, patterns, or words that come together.

\subsection{Coloring the Kokeshi doll}

Coloring is an activity to bring color to an image. Creating artistic images can build confidence in special needs children. This activity can stimulate sensitivity, coordination, confidence, and creativity. During any activity, be sure to use safety equipment and tools [4].

Children are instructed to color the doll with tools and paper supplies, including the kokeshi dolls and crayons, or other painting tools. Children love to paint through different media, both by drawing and filling in the picture fields to color.

\subsection{Handcrafting (Koi Fish)}

The koi fish symbolizes long life/ many children play this game with the hope to grow well and live a healthy and long life.

Tools: scissors, glue, wood, threads rami, double tip tape. Equipment: colorful paper, crepe paper, eye trinkets.

How to make the Koi:

1. Prepare a $10 \times 15 \mathrm{~cm}$ for the fish body

2. Cut out a half-circle part of the cardboard in the shape of fish scales

3. Attach the fish-shaped cardboard onto the cardboard using glue.

4. Cut crepe paper into a rectangle for the fishtail decoration and tape it with the double tip tape. 
5. Roll up the decorated cardboard until it is round and tape it with the double tip tape.

6. Prepare the wood and rami, thread, and tie it to the wood.

7. Make holes on both sides of the fish-shaped cardboard until it looks like the picture.

8. The crafts are finished and ready to be played or hung as decoration.

\subsection{Handcrafting (Hinamatsuri)}

Hinamatsuri in the past has used a symbol of respect or achievement for women. Hinamatsuri meant the woman's day. It also symbolizes the grace and beauty of a woman, also the importance of a woman.

Tools: scissor, double tip, glue, crayon/coloring. Material: white paperboard.

How to make:

1. Prepared the paperboard that had a motive and then colored it as a wish.

2. Cut the paperboard as an object.

3. Combine those papers until it has person-shaped.

4. Then shape as a picture, and paper is ready to play.

\subsection{Origami}

The art of paper folding is called origami in Japan. The word origami consists of two words, namely oru and us. Oru means fold and what we mean is paper. Folding is a crafting activity to make specific shapes without using adhesives (glue). This activity requires eye and hand coordination, skills, thoroughness, neatness, and creativity. If this activity is in accordance with the child's interests, it will provide joy, preoccupation, and satisfaction for the child.

How to make:

1. Prepare a square-shaped paper.

2. Then fold into a rectangular shape as well as the other side.

3. Then fold the triangular-shaped paper as well as the other side.

4. Fold the paper like figure 4 below at each corner of the paper (4 times total).

5. Unite each corner of the paper to form figure 5 as below.
6. After each corner is put together, open the front and back folds.

7. Fold each corner on the right and left sides to the center.

8. The folded corners are then put together to open the other side.

9. Fold the ungrouping paper upwards.

10. Once folded, open the fold on the other side.

11.Open the front and back folds so that the wings are formed.

12. Fold the middle paper to form the head and tail of the bird.

In every meeting, each group of children is accompanied to play the existing games. At first, they were shown how to play it, then asked to do it themselves, with directions from a companion. This activity is repeated at each meeting until the child masters the game. Assessment of the program's success is carried out by looking at the progress of the group's abilities, starting from the first meeting to the last meeting.

After the children can master the game, the activity continues to evaluate the implementation and the evaluation to measure the effectiveness of the program and its target. In this process, the team PKM-PM held discussions with teachers and child psychology experts who accompanied the team. In mentoring SLB Negeri 1 Makassar teachers, the team provided re-training or re-implementation to students who were not the target of the previous program. The chaperoning teachers are taught how to intervene with children using the game media.

The promotion technique was carried out using socialization to accompany teachers and parents/guardians regarding the program implementation plan at SLB Negeri 1 Makassar. Furthermore, the counseling technique was carried out using socialization to accompany teachers and parents/guardians regarding the SLB Negeri 1 Makassar program implementation plan. Furthermore, the team and the accompanying teachers discussed the problems and obstacles students face in obtaining information and understanding how to approach and communicate with students targeted in implementing the program. In addition, the team also provides guidance and consultation to child psychologists to find the best method for intervening with children. This initial activity was carried out as an effort by the team to understand the world of extraordinary education, which is very useful in implementing the program. 


\section{RESULT AND DISCUSSION}

The results obtained refer to short-term success indicators. The implementation of this program can be seen from the assessments made by mentors and teachers accompanying students collected. Of course, there are changes to activities and additional activities in implementing the activities when carried out. However, this can be overcome by coordinating and consulting with teachers and child psychologists.

Based on the changes in children's abilities, the graph below represents the increase in abilities achieved during the program's implementation.

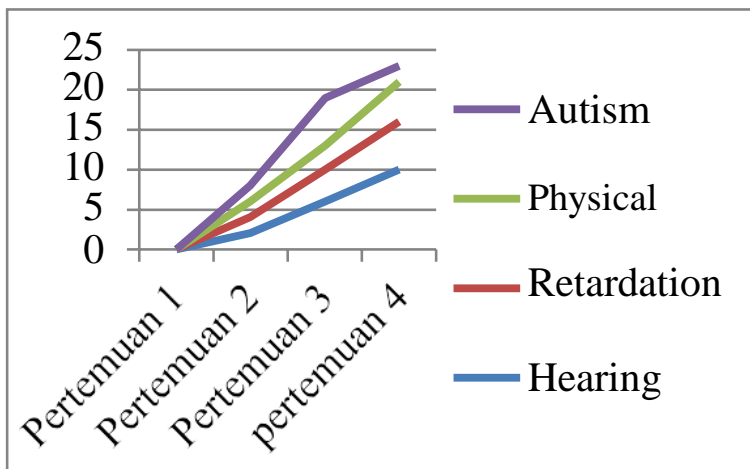

Figure 1. Assessment of the result of DisabilityPlay Therapy

The assessment results by the team and the accompanying teacher showed that the implementation of this program succeeded in reducing the level of boredom in children, which had been experienced for more than a year. This was also conveyed by the parents/guardians of students, who explained that they were delighted with this program because it could provide mental health assistance and support for their children, even more so at this time.

We still applied the same traditional Japanese games to children with disabilities at the second meeting. They can already play traditional Japanese games even though the team is still guiding in playing. They have started to distinguish directions (left and right) and distinguish body parts, and children are starting to focus and interact actively with the team and volunteers. Children begin to show their emotions in the game, such as always wanting to excel and be more advanced in playing the game.

At the third meeting with the same game, they had started to get used to it and had a competitive spirit wanting to be the best in creativity and activity. They have also expressed happy expressions while playing and never give up on playing games that test their creativity.

At the fourth meeting, the assessment results improved and developed children's abilities in play guidance activities carried out by each member who had succeeded in gradually increasing the child's abilities. The assessment results that the team and accompanying teachers have carried out show students' success in fine motor development through games that can stimulate or stimulate the environment that can help the growth and development of children's intelligence. Through play guidance which is repeated gradually, it is seen that the ability of children with mental retardation and autism is seen to slowly develop, such as hand movement skills, problem-solving from games, and children's trust and social skills. From the game, the characters presented by the team showed an increase in their imagination through the games of fukuwarai, kokeshi, and hinamatsuri. Children with special needs can recognize abstract and spontaneous concepts through these games. When assembling and composing shapes, games of fukuwarai, kokeshi, and hinamatsuri help children develop creativity for children, especially Children with Special Needs. As for the sustainability of the program, below are the next stages of the program:

1. Provision of new media of games by repairing or buying games that have been damaged during the activity so that the school can continue to implement the activity for the students of SLB Negeri 1 Makassar.

2. We follow up on activities or schools that implement the program independently to get expected results so that the program's implementation runs well in the school.

\section{CONCLUSION}

After conducting the mentoring and play guidance, the PKM-PM team has seen the development of children with disabilities successfully playing traditional Japanese games, including improving cognitive abilities, fine motor skills, and creativity. In addition, after the SLB teacher team's guidance, they have also been able to apply the play therapy method to children with disabilities. The creativity and fine motor skills of children with disabilities have increased every meeting, proving that traditional Japanese game media has successfully implemented the play therapy method for children with disabilities.

\section{FUNDING \& ACKNOWLEDGMENTS}

We thank the Directorate General of Higher Education, Research, and Technology, Ministry of Education, Culture, Research, and Technology of the Republic of Indonesia for funding PKM in 2021, and Hasanuddin University for supporting the implementation of this activity. 


\section{REFERENCES}

[1] Mutiah, D. 2010. Psikologi Bermain Anak Usia Dini. Kencana: Jakarta.

[2] Nur H. 2013. Membangun Karakter Anak Melalui Permainan Tradisional. Jurnal Pendidikan Karakter. Nomor 1:90.

[3] Novitasari. 2017. Efektifitas Model Pembelajaran Team Game Tournament (TGT) dengan Menggunakan Media Fukuwarai untuk Meningkatkan Penguasaan Huruf Hiragana. Edujapan, 106.

[4] Sulistyaningtyas, R. A. 2019. The Implementation of Traditional Games for Early Childhood Education. Atlantis Press: In 3rd International Conference on Current Issues in Education. 